\title{
Aerosol particle size distributions in the lower Fraser Valley: evidence for particle nucleation and growth
}

\author{
M. Mozurkewich, T.-W. Chan, Y.-A. Aklilu, and B. Verheggen \\ Dept. of Chemistry and Centre for Atmospheric Chemistry, York Univ., 4700 Keele Street, Toronto, ON M3J 1P3, Canada
}

Received: 20 January 2004 - Published in Atmos. Chem. Phys. Discuss.: 16 March 2004

Revised: 27 May 2004 - Accepted: 23 June 2004 - Published: 6 July 2004

\begin{abstract}
Particle size distributions from 9 to $640 \mathrm{~nm}$ diameter were measured at Eagle Ridge in the lower Fraser Valley from 13 August to 1 September 2001 as part of the Pacific 2001 Air Quality Study. The site was on top of a ridge, about $300 \mathrm{~m}$ above the valley floor, in a predominantly agricultural area about $70 \mathrm{~km}$ ESE of Vancouver. To further characterize the particles, their hygroscopic properties (affinity for water) were measured. The maximum of the number distributions was generally between 40 and $100 \mathrm{~nm}$ diameter, but the number distribution was sometimes dominated by ultrafine particles with diameters below $40 \mathrm{~nm}$. These ultrafine particles, which appeared to some extent on all days, were frequently associated with elevated levels of $\mathrm{CO}$ and $\mathrm{NO}_{\mathrm{x}}$, as expected for fresh vehicular emissions. The appearance of these fresh emissions was most pronounced when the growing mixed layer reached the altitude of the site. In contrast, pronounced nucleation events occurred on the five cleanest days; these resulted in particle number concentrations as high as $5 \times 10^{4}$ particles $\mathrm{cm}^{-3}$ and growth rates of 5 to $10 \mathrm{~nm} \mathrm{hr}^{-1}$. Nucleation appears to have been triggered when the UV flux reached about $25 \mathrm{~W} \mathrm{~m}^{-2}$. The growth of these newly formed particles was probably driven by the photochemical oxidation of biogenic organic compounds. Dramatic growth events were also observed on the afternoons of the more polluted days; these produced an extremely narrow mode $(\sigma<0.3)$ at a diameter of about $40 \mathrm{~nm}$. Rainy days showed low number concentrations with the size distributions shifted to small sizes. On one of these days there was evidence of nucleation not far from the site; this may have been occurring in the vicinity of the clouds.
\end{abstract}

\footnotetext{
Correspondence to: M. Mozurkewich

(mozurkew@yorku.ca)
}

\section{Introduction}

Atmospheric particles contribute to climate change directly by scattering sunlight (Schwartz, 1996) and indirectly by changing the radiative properties and lifetime of clouds (Twomey, 1991). Particulate matter also has adverse health effects (Oberdörster, 2000) and reduces visibility (Pryor and Barthelmie, 2000). All of these effects depend not only on the mass of particulate matter but also on how that mass is distributed as a function of particle size. The lower Fraser Valley is often impacted by episodes of poor air quality and low visibility. It contains the city of Vancouver, a large urban area with associated emissions from traffic and industry. Through most of the valley, intensive agriculture is practiced, with associated emissions of ammonia. The valley is surrounded by dense forests, emitting biogenic volatile organic compounds (VOCs). The reduction of visibility, which often occurs in this area of natural beauty, is regarded as a major problem (Li, 2004). For an overview of the objectives and background information for the field campaign of which this work is a part, see $\mathrm{Li}$ (2004).

Submicrometer aerosol particles are formed largely by gas-to-particle conversion. The oxidation of precursors, such as $\mathrm{SO}_{2}, \mathrm{NO}_{2}$, and suitable organic compounds, can produce compounds with very low vapor pressures. These then enter the particle phase either individually or in combination with other species, such as water vapor and $\mathrm{NH}_{3}$. This can result in the formation of new particles via nucleation, or in the growth of existing particles via condensation. The existing particles may have been formed at an earlier time by nucleation or they may have been directly emitted. Particles may also grow by coagulation. Particle size distributions in the atmosphere are a result of all these processes.

The measurements reported here were undertaken in order to gain a better understanding of these processes. Particle size distributions from 9 to $640 \mathrm{~nm}$ diameter were measured at Eagle Ridge $(300 \mathrm{~m}$ altitude), located in the 


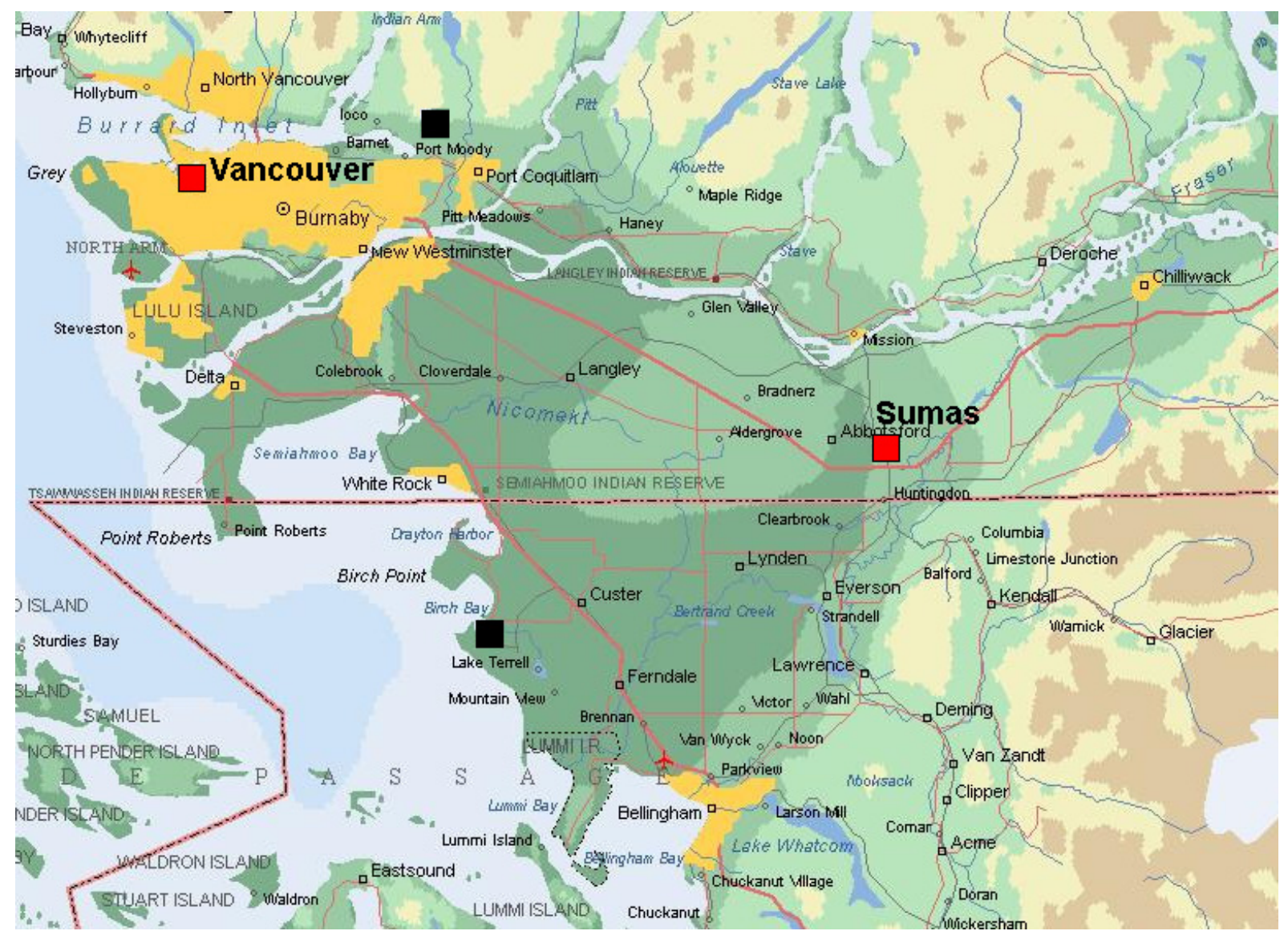

Fig. 1. The lower Fraser Valley. The red squares indicate the measurement site at Sumas mountain (Eagle Ridge) and downtown Vancouver; the black squares indicate the oil refineries at Port Moody and Point Whitehorn. Orange shading indicates urban areas. The prevailing air flow at the Sumas site was from the southwest.

Lower Fraser Valley, approximately $70 \mathrm{~km}$ ESE of Vancouver, British Columbia, see Fig. 1. To further characterize the particles, we measured their hygroscopic properties (affinity for water); this provides information on the relative amounts of organic (hydrophobic) and inorganic (hydrophilic) material in the particles.

The presence of these different sources and processes was reflected in the size distributions observed during different air mass regimes that were encountered. Some major findings, related to aerosol dynamics, of each of these periods will be discussed in this paper. Ultrafine particles, with diameters less than $40 \mathrm{~nm}$, were detected on most days during this study, even during the rainy periods. On five days we observed nucleation events; the source of the ultrafine particles in the other cases was likely direct emission. We also observed significant growth events that were likely the result of both condensation and coagulation.

The conditions under which nucleation occurs in the atmosphere are still incompletely understood. Most reported observations of nucleation have been in more remote locations. These have included coastal areas (O'Dowd et al., 2002; Weber et al., 1998), the marine boundary layer (Covert et al., 1992; Weber et al., 1995), the Arctic (O'Dowd et al., 1997; Wiedensohler et al., 1996), the free troposphere (Clarke, 1992; de Reus et al., 1998), the vicinity of clouds (Hegg et al., 1990; Clarke et al., 1999), remote continental areas (Weber et al., 1997; Birmili et al., 2000), over continental forests (Mäkelä et al., 1997; Leaitch et al., 1999; Kulmala et al., 2001b), in semi-rural areas (Birmili and Wiedensohler, 2000; Verheggen and Mozurkewich, 2002) and in urban areas (Woo et al., 2001; Stanier et al., 2004). Thus, it is clear that nucleation can occur in almost any environment, subject to a favorable set of conditions; these seems to include a suitable source of condensable vapor, high UV radiation intensity, low aerosol surface area, and high relative humidity although not all reports agree on the necessity of all these factors. It is noteworthy that of these locations, only nucleation in the free troposphere and in the vicinity of clouds seem to agree with predictions by classical nucleation theory.

There have been a number of estimates of the diameter growth rates of atmospheric particles in a variety of environments. There are several reports for clean, mountain sites: $2.1 \mathrm{~nm} \mathrm{hr}^{-1}$ (Birmili et al., 2000), $1.6 \mathrm{~nm} \mathrm{hr}^{-1}$ (Weber et al., 1997), and 3 to $4.5 \mathrm{~nm} \mathrm{hr}^{-1}$ (Weingartner et al., 1999). 
Similar growth rates of 2 to $3 \mathrm{~nm} \mathrm{hr}^{-1}$ have been reported for sites in the boreal forest (Mäkelä et al., 1997; Leaitch et al., 1999; Kulmala et al., 2001a), 2 to $5 \mathrm{~nm} \mathrm{hr}^{-1}$ over the south Pacific (Weber et al., 1998), and $4.8 \mathrm{~nm} \mathrm{hr}^{-1}$ for a rural area impacted by high $\mathrm{SO}_{2}$ (Verheggen and Mozurkewich, 2002). Dramatically larger growth rates of 360 to $1200 \mathrm{~nm} \mathrm{hr}^{-1}$ have been reported by O'Dowd et al. (2002) for a site on the coast of Ireland.

\section{Experimental}

The measurements described here were made as part of the Pacific 2001 Air Quality Study at the Eagle Ridge site on Sumas Mountain, just east of Abbotsford, British Columbia, Canada. The site was at $49^{\circ} 03^{\prime} 08^{\prime \prime} \mathrm{N}, 122^{\circ} 14^{\prime} 43^{\prime} \mathrm{W}$, at the top of the ridge at an elevation of $300 \mathrm{~m}$ above sea level. The site was in a clearing surrounded by a mixture of coniferous and deciduous trees. The site was above the nocturnal inversion, when one formed, but within the daytime mixed layer. This site was expected to be affected by urban, agricultural, and biogenic emissions. The most important local emissions are thought to be ammonia emissions from an agricultural area beginning about $3 \mathrm{~km}$ to the south and traffic emissions from a major highway about $3 \mathrm{~km}$ to the south and from the town of Abbotsford, beginning about $3 \mathrm{~km}$ to the west. Abbotsford is a town of approximately 100000 inhabitants with some light industry and is located about $70 \mathrm{~km}$ from the major urban center of Vancouver. The surrounding portion of the Fraser Valley is largely agricultural and is surrounded by forested mountains. The area suffers significant degradation of visibility in the summer. Full details about the site are given by Li (2004). Measurements began on the afternoon of 13 August and continued until the morning of 1 September.

\subsection{Particle size distributions and number concentrations}

Air was sampled by drawing about 23 alpm (actual liters per minute) through a $3 / 8$ inch stainless steel tube that had an inverted U-shape inlet to prevent rain drops from getting into the sample line. The inlet was located $2 \mathrm{~m}$ above the top of the trailer. Two flows were drawn off from this using center-line samplers. First, about 6 alpm were sampled by a Differential Mobility Analyzer (DMA, TSI 3071); a portion $(1.00 \pm 0.03 \mathrm{alpm}$, error limits are standard deviations of the recorded values) was drawn through a center-line sampler to form the polydisperse aerosol flow, the rest $(4.97 \pm 0.04 \mathrm{alpm})$ was filtered and used as the sheath air flow; thus both flows had the same humidity. The aerosol was not dried but the relative humidity and temperature of the sheath air were monitored using a Vaisala model 50Y sensor and continuously recorded. A second flow of $1.4 \mathrm{alpm}$ was drawn off from the main sample flow to a TSI 3022 Condensation Particle Counter (CPC) for monitoring the total number concentration.
The DMA sheath air and excess air were measured by mass flow meters; the former was recorded continuously using the data system and the latter was checked manually at least once per day. The sheath and excess flows balanced to within $2 \%$ (usually to better than $1 \%$ ). A TSI 3010 CPC sampled the entire monodisperse aerosol flow $(0.994 \pm 0.013 \mathrm{alpm})$ from the DMA; this flow was controlled by the critical orifice in the CPC. The DMA aerosol flows were monitored by measuring the pressure drops across calibrated laminar flow elements which were checked manually at least once per day.

The DMA voltage was scanned exponentially from 10 volts to 10000 volts every 5 min using a $270 \mathrm{~s}$ upscan and $30 \mathrm{~s}$ downscan; this allowed the sampling of particles from $8.6 \mathrm{~nm}$ to $649 \mathrm{~nm}$ in diameter. This ramp voltage was controlled by the analog output of the 3010 CPC and the counts from the CPC were totaled and saved every two seconds. Under the conditions that obtained in this study, the upper size limit was sufficient to cover virtually the entire number distribution; this enabled us to avoid the inversion instabilities that occur when the distribution is truncated at larger sizes. With the $3010 \mathrm{CPC}$, counting statistics were sufficient that the resulting distributions had little noise. The counting efficiency of the CPC is less than unity at smaller sizes; a correction was made for this using the data of Buzorius et al. (2001).

The counts versus voltage distributions were converted into number distributions by accounting for the CPC flow, the DMA time delay (measured in the lab using monodisperse particles), the DMA transfer function, and the charging efficiencies of the $\mathrm{Kr}^{85}$ bipolar charger (using the values provided by TSI). These efficiencies were also used to correct for multiple charging by propagating the correction downward from the largest measured size, this produced no sign of instability in the distributions. The final size distributions consist of 30 size bins with the same diameters as used by TSI's SMPS software with 16 bins per decade.

The TSI model 3022 CPC, used to measure the total number concentration of particles, detects $50 \%$ of particles with diameters of $6 \mathrm{~nm}$ and detects some particles with diameters as small as $3 \mathrm{~nm}$. In the following, the concentration measured by this instrument will be referred to as the CPC concentration. The CPC has nearly $100 \%$ detection in the size range covered by the DMA. Thus, in the absence of particles below the $9 \mathrm{~nm}$ lower size limit of the DMA, the CPC should agree with the integrated DMA number concentration; otherwise, it should be larger than the DMA total. The 3022 uses single particle counting for concentrations below $10^{4} \mathrm{~cm}^{-3}$ and uses a photometric method for higher concentrations. The latter is much less accurate since it is subject to drifts in both the zero and slope. During this study, we obtained excellent agreement $( \pm 5 \%)$ between the CPC and DMA totals when the CPC was in single particle mode on nights during which virtually all particles were above the lower size limit of the DMA. 


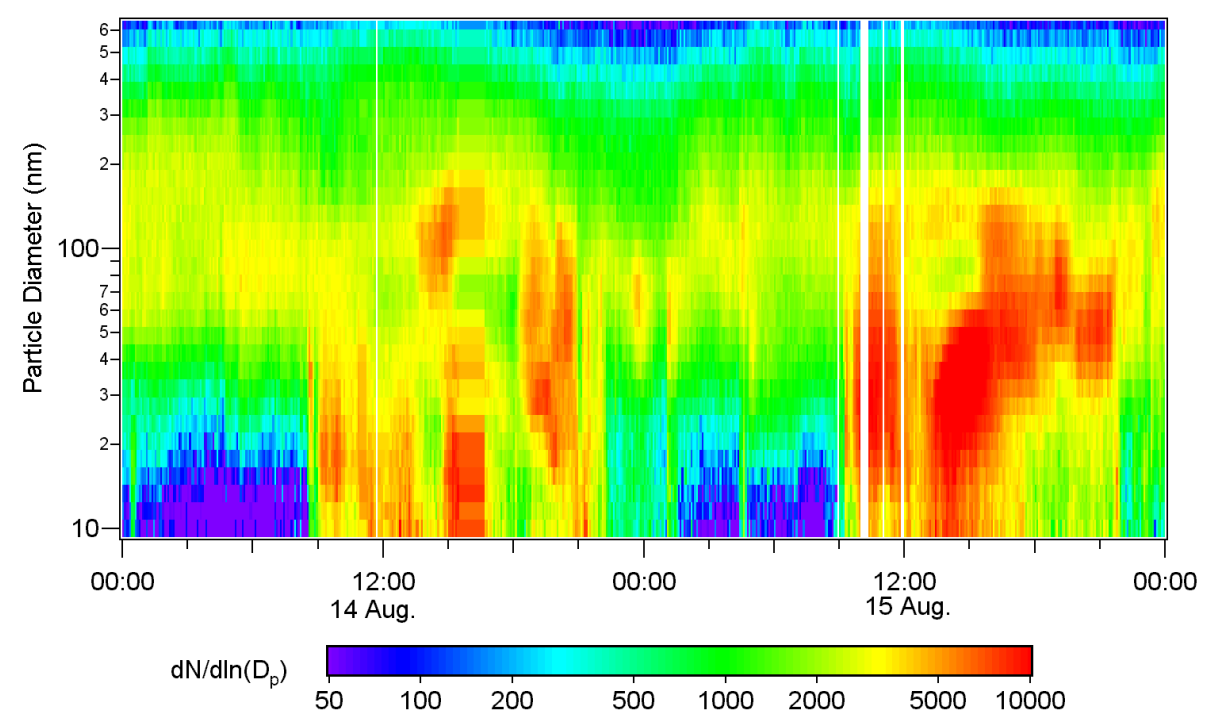

Fig. 2. DMA number size distributions, in 30 size bins (vertical axis) at 5 min intervals (horizontal axis) for 14 and 15 August 2001 at Eagle Ridge. Color coding gives the concentration, $\mathrm{d} N / \mathrm{d} \ln \left(D_{p}\right)$, on a logarithmic scale for each bin and time interval.

\subsection{Hygroscopic TDMA}

This instrument was used to estimate the inorganic/organic (soluble/insoluble) fractions and the mixed state of the aerosol at certain discrete sizes. Full details of the method and a more in depth discussion of the results are given by Aklilu and Mozurkewich (2004). Briefly, the sampled aerosol was dried, a monodisperse fraction was selected using DMA \#1, this monodisperse aerosol was humidified in a "conditioner", and the resulting size distribution was measured by DMA \#2. The dried particle size alternated between two values. One size was always $114 \mathrm{~nm}$ diameter and the other was usually $50 \mathrm{~nm}$ but $160 \mathrm{~nm}$ was used when there were insufficient particles at $50 \mathrm{~nm}$. The conditioner relative humidity was scanned from roughly $50 \%$ to $80 \%$ over a two hour cycle.

The humidified particles sometimes showed a single "less hygroscopic" (organic) mode, sometimes showed a single "more hygroscopic" mode, and sometimes showed both. A "growth factor" (wet/dry diameter) was determined for each mode. The two modes only separated at relative humidities above the deliquescence point $(69 \% \mathrm{RH})$ of letovicite, $\left(\mathrm{NH}_{4}\right)_{3} \mathrm{H}\left(\mathrm{SO}_{4}\right)_{2}$. The less hygroscopic mode, when present, always had roughly the same weak dependence of growth factor on relative humidity, reaching just 1.09 at $80 \% \mathrm{RH}$. This is typical of what is expected for organic particles (Peng et al., 2001; Dick et al., 2000; Virkkula et al., 1999) and so these particles were assumed to be purely organic. The more hygroscopic mode had growth factors between those of the organic mode and those expected for letovicite. These growth factors were used to estimate the organic volume fraction in the more hygroscopic particles on the assumptions that the inorganic fraction was letovicite (the results changed by about $3 \%$ if $\left(\mathrm{NH}_{4}\right)_{2} \mathrm{SO}_{4}$ was assumed) and that the organic fraction growth was described by the typical growth of the less hygroscopic mode. These were then combined with the fraction in each mode to obtain an overall organic fraction for particles of the size samples; only these overall fractions are considered here. It was only possible to obtain these fractions when the conditioner relative humidity was at or above $75 \%$. Because of the assumptions made, the organic fractions should be regarded as an estimate of the relative amounts of organic and inorganic material rather than as a precise measure.

\section{Results and discussion}

At the start of the study, the air quality at the site was characterized by heavy smog and very poor visibility. There were two distinctive features observed during this period: the transport of freshly emitted ultrafine particles and dramatic afternoon growth events. A transition to cleaner air took place on 16 August; on each of the following four days we observed large nucleation events, apparently driven by the oxidation of biogenic organic compounds. Frequent rain was encountered on 21 through 23 August. Nucleation mode particles were observed sporadically on these rainy days; at times these appeared to be due to emissions and at times due to nearby nucleation. During the remainder of the study conditions were variable, with some polluted days (though not as severe as at the beginning of the study) and some relatively clean days. The night of 27 to 28 August was unique during this study in that particle growth continued through the night. 29 and 30 August showed some of the largest aerosol mass concentrations observed at Eagle Ridge although visibility 


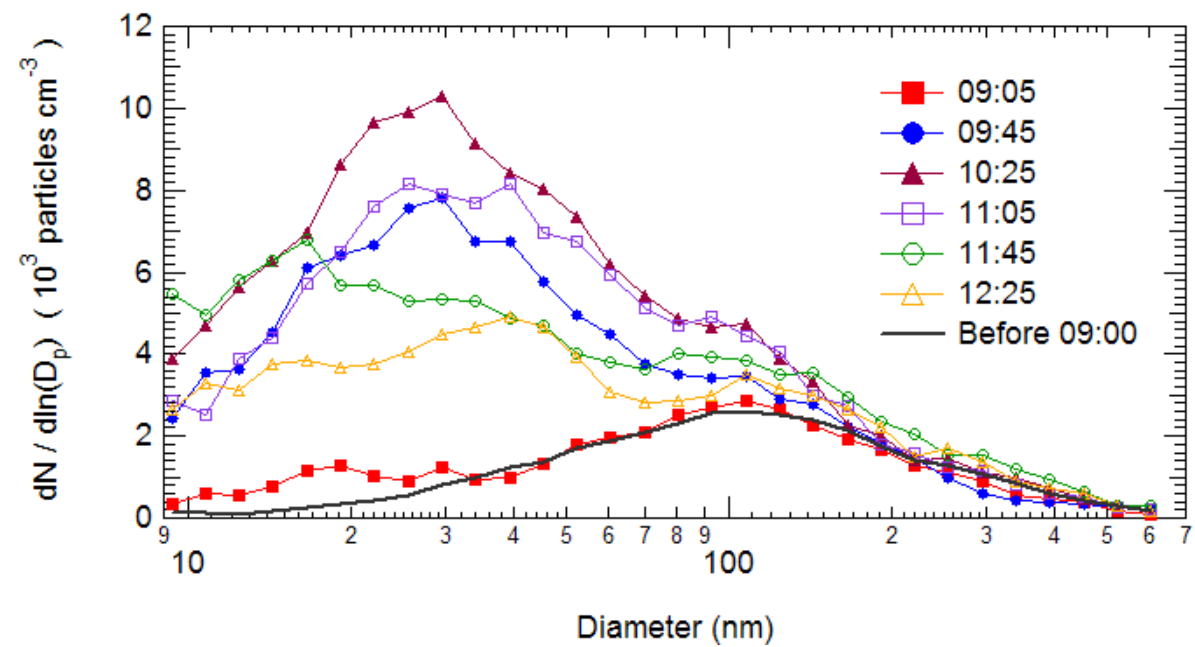

Fig. 3. Size distributions in the growing boundary layer on the morning of 15 August. Times are for the start of each five minute scan; for clarity, only every eighth scan is shown. The heavy solid line is the average of the distributions in the residual boundary layer from 08:00 through 08:55.

was not as poor and $\mathrm{O}_{3}$ concentrations were not as high as at the start of the study. On 31 August a morning rainfall was followed by a nucleation event similar to those observed during the clean period.

In the following, we first discuss the polluted days (15, 2728, 30 August) then the nucleation days (17-20, 31 August) and finally the rain days (22-23 August). Local solar noon was 13:14 on 14 August and 13:09 on 31 August. All times are Pacific Daylight Time (UT -7 h).

\subsection{Polluted days}

\subsubsection{Smog episode: Wednesday, 15 August}

At the beginning of the study; the lower Fraser Valley was experiencing an air pollution episode with very low visibility. An upper level ridge blocked air flow out of the valley and suppressed daytime mixing heights to below $1000 \mathrm{~m}$. Strong nocturnal inversions formed at night; the Eagle Ridge site was well above the top of those inversions. The growing mixed layer reached the site in mid-morning (09:00 to 10:00), as indicated by large increases in $\mathrm{NO}_{\mathrm{x}}$ and $\mathrm{CO}$ and a decrease in $\mathrm{O}_{3}$.

Wednesday, 15 August was typical of days during this period; a plot of all the particle number size distributions for this day is given in Fig. 2. During the early morning hours the total number concentrations and particle size distributions were nearly constant except in the smallest size bins where there were occasional low concentrations of particles. Prior to 09:00, the site was within the residual boundary layer from the preceding day and the size distributions were nearly constant (to within 5\%), with a maximum at about $100 \mathrm{~nm}$ diameter.
Shortly after 09:00 the size distributions began to change dramatically with the appearance of large concentrations of ultrafine particles. However, this was not due to nucleation. Simultaneous changes in $\mathrm{NO}_{\mathrm{x}}, \mathrm{O}_{3}$, and $\mathrm{CO}$ indicate that this resulted from the upward mixing of air that had been trapped under the nocturnal inversion. The total DMA concentration increased from 5000 particles $\mathrm{cm}^{-3}$ before 09:00 to $21000 \mathrm{~cm}^{-3}$ at $10: 30$ then declined to $12000 \mathrm{~cm}^{-3}$ over the following two hours. The evolution of the size distributions during this time is shown in Fig. 3. The changes in concentration were due to an Aitken mode centered at about $25 \mathrm{~nm}$; the shoulder at $100 \mathrm{~nm}$ corresponds to the accumulation mode aerosol present in the residual boundary layer before 09:00.

Fitting these distributions to bimodal log-normal distributions shows that they can be described by an accumulation mode consisting of about 5000 particles $\mathrm{cm}^{-3}$ with a number median diameter, $D_{N M D}$, of $100 \mathrm{~nm}$ and a logarithmic standard deviation, $\sigma$, of 0.80 (as observed before 09:00) and a freshly emitted Aitken mode consisting of up to 17000 particles $\mathrm{cm}^{-3}$ (at 10:30) with $D_{N M D}=24.5 \mathrm{~nm}$ and $\sigma=0.77$.

The above results are consistent with dilution by air containing the same aerosol as in the residual boundary layer. This is supported by the $\mathrm{CO}$ and $\mathrm{NO}_{\mathrm{x}}$ measurements; these are shown in Fig. 4 along with the integrated DMA number. Throughout the period of boundary layer growth (until 12:40) the $\mathrm{CO}, \mathrm{NO}_{\mathrm{x}}$, and integrated number concentrations track each other well. At 11:00 the measured boundary layer heights at both Langley (at $82 \mathrm{~m}$ elevation about $24 \mathrm{~km} \mathrm{~W}$ by NW of the site) and Chilliwack (at $10 \mathrm{~m}$ elevation about $25 \mathrm{~km}$ to the ENE) were about $500 \mathrm{~m}$ (Snyder and Strawbridge, 2004), so these observations suggest that at 


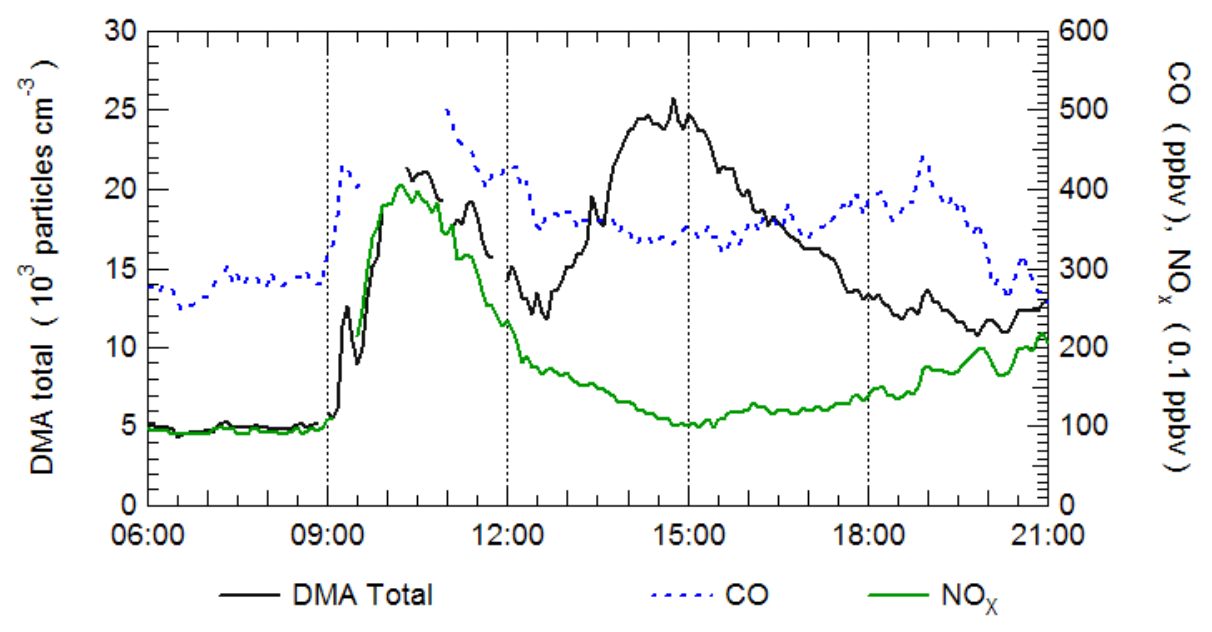

Fig. 4. Integrated DMA number concentrations and mixing ratios of $\mathrm{CO}$ and $\mathrm{NO}_{\mathrm{x}}$ for 15 August. Before 12:40 all three behave as expected for elevated site observations of surface emissions in a growing boundary layer. From 12:40 until after 18:00 the aerosol varies independently of the $\mathrm{CO}$ and $\mathrm{NO}_{\mathrm{X}}$.

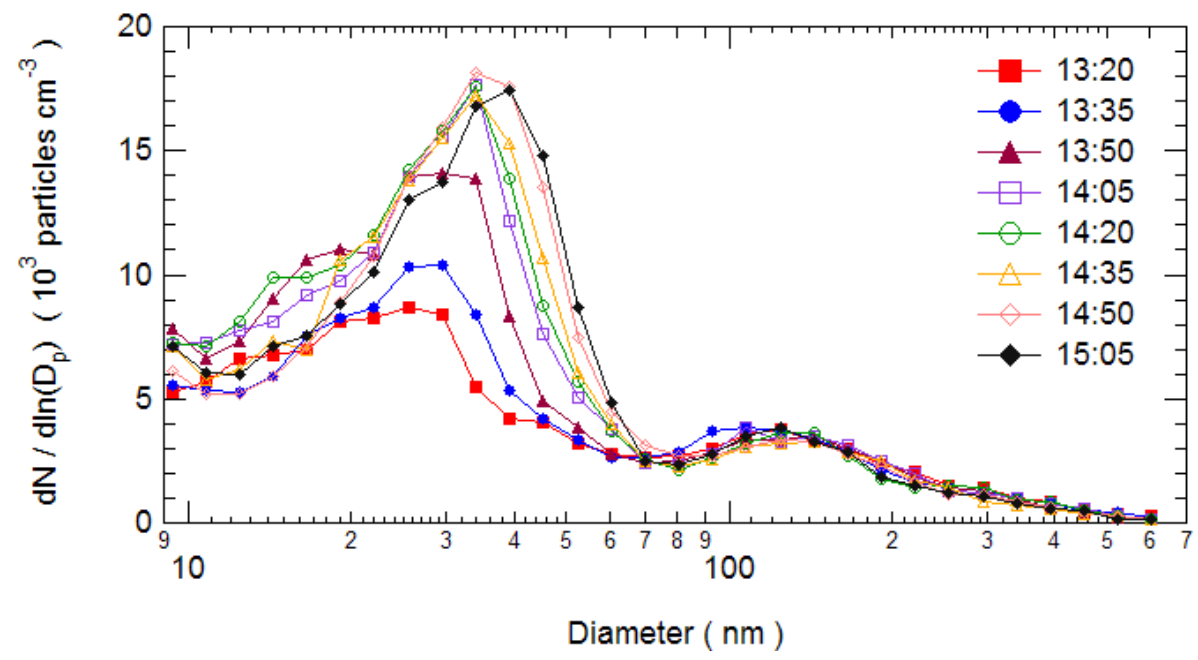

Fig. 5. Evolution of particle size distributions due to particle growth on the afternoon of 15 August. Times are for the start of each five minute scan. For clarity, only every third scan is shown.

Eagle Ridge the boundary layer continued to grow to a depth of about $1000 \mathrm{~m}$ after 12:30. This is in agreement with the depth of $900 \mathrm{~m}$ measured at Chilliwack at 17:00 (Snyder and Strawbridge, 2004).

The observations imply that the number concentration under the nocturnal inversion was of the order of $8 \times 10^{4} \mathrm{~cm}^{-3}$ which suggests that coagulation within the Aitken mode was important in reducing the number and increasing the average size of these particles. Here we estimate coagulation rate constants using the method of Sceats (1989) with Hamaker constants as measured for aqueous sulfuric acid by Chan and Mozurkewich (2001). Although the particles encountered in this study are not pure $\mathrm{H}_{2} \mathrm{SO}_{4} / \mathrm{H}_{2} \mathrm{O}$, coagulation rate constants are not very sensitive to the Hamaker constant for mod- est changes from the value assumed here. Thus, the estimates made using this assumption should be reasonable. For identical particles with diameters of 15 to $25 \mathrm{~nm}$, we estimate the coagulation rate constants to be $2.2 \times 10^{-9} \mathrm{~cm}^{3} \mathrm{~s}^{-1}$. For a concentration of $8 \times 10^{4} \mathrm{~cm}^{-3}$, this gives a number concentration lifetime of $95 \mathrm{~min}$. So we expect that these particles had undergone a significant amount of coagulation and were larger and less numerous than the particles originally emitted. In addition, the number would have also been reduced by coagulation with particles in the accumulation mode centered at $100 \mathrm{~nm}$. The association of these particles with $\mathrm{CO}$ and $\mathrm{NO}_{\mathrm{x}}$ suggests that they were the result of vehicular emissions. 


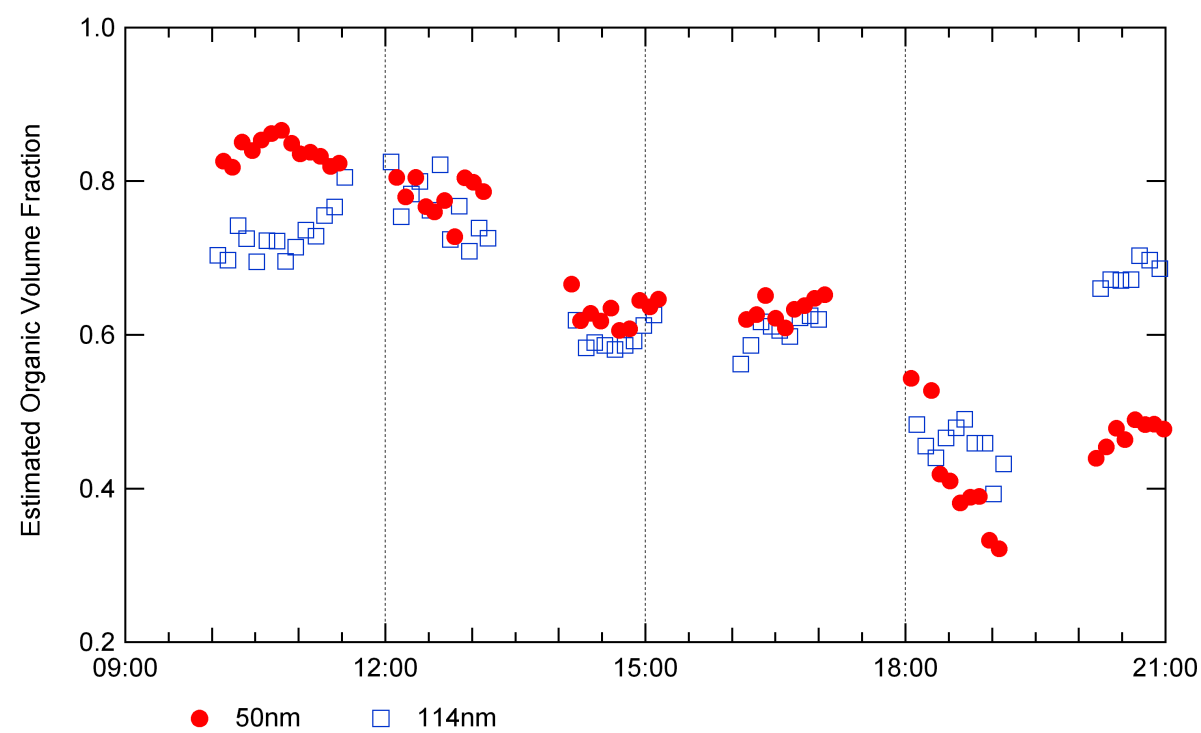

Fig. 6. Organic (i.e. non-hygroscopic) volume fraction determined by the hTDMA showing the decrease of the organic fraction during the growth event on the afternoon of 15 August.

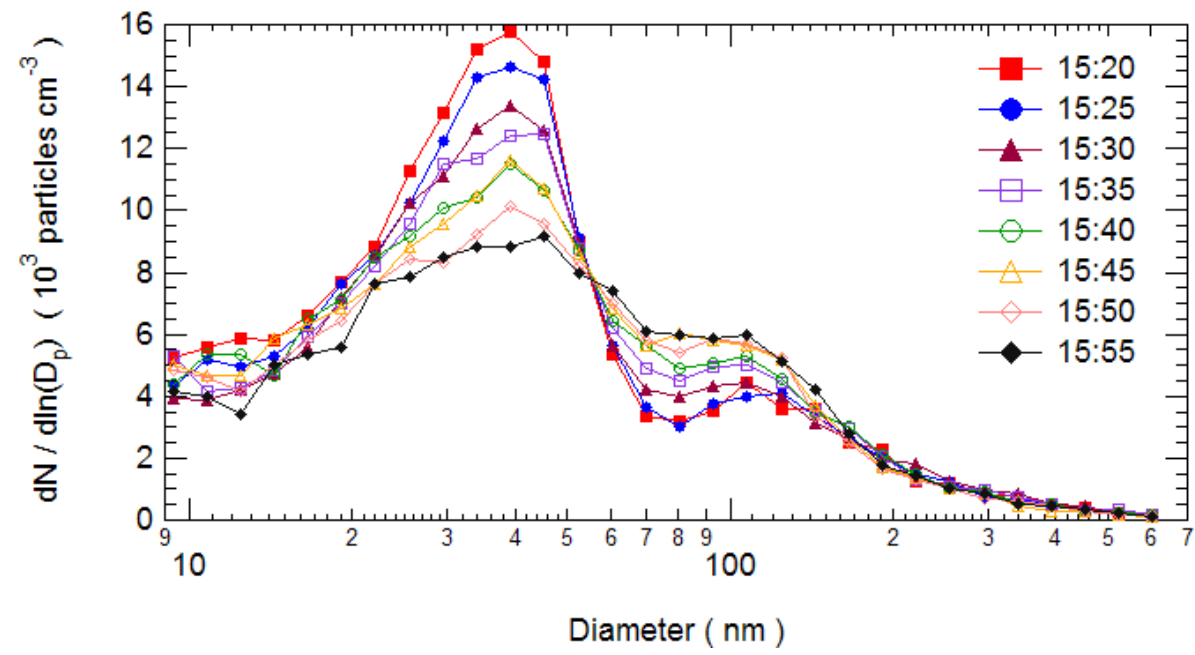

Fig. 7. Mixing of air masses on the afternoon of 15 August; the mode at $40 \mathrm{~nm}$ decreases while the mode at $100 \mathrm{~nm}$ increases. Times are for the start of each five minute scan.

After about 11:40, the number maximum moved to just $20 \mathrm{~nm}$; this may have been due to less coagulation of the freshly emitted particles. After this time, $\mathrm{d} N / \mathrm{d} \ln D_{p}$ was in excess of 5000 particles $\mathrm{cm}^{-3}$ for diameters between 10 and $20 \mathrm{~nm}$. Using the measured size distributions, calculated lifetimes with respect to coagulation with all larger particles varied from just over three hours for $19 \mathrm{~nm}$ particles to just over one hour for $9 \mathrm{~nm}$ particles. Since a significant concentration of these ultrafine particles continued throughout the afternoon, there must have been a continuing source of these particles. Good agreement between the CPC and DMA totals indicates that this was not due to local homogeneous nucleation, since there were not a large number of particles below the lower size limit of the DMA. It is likely that the source was the same as for the particles transported to the site in the growing boundary layer.

After 13:00 a distinct mode appeared at about $20 \mathrm{~nm}$ and began a dramatic period of growth that lasted until about 15:20, when the mode maximum was at about $40 \mathrm{~nm}$. Representative distributions are shown in Fig. 5. During this time, the integrated DMA number concentration increased from about 12000 to $24000 \mathrm{~cm}^{-3}$. The size distributions during this growth period can be well fit by trimodal lognormal distributions. The accumulation mode had shifted to a larger size $\left(D_{N M D}=130 \mathrm{~nm}\right)$ and became narrower $(\sigma=0.50)$ than observed in the morning; the number concentration, $\mathrm{N}$, in 


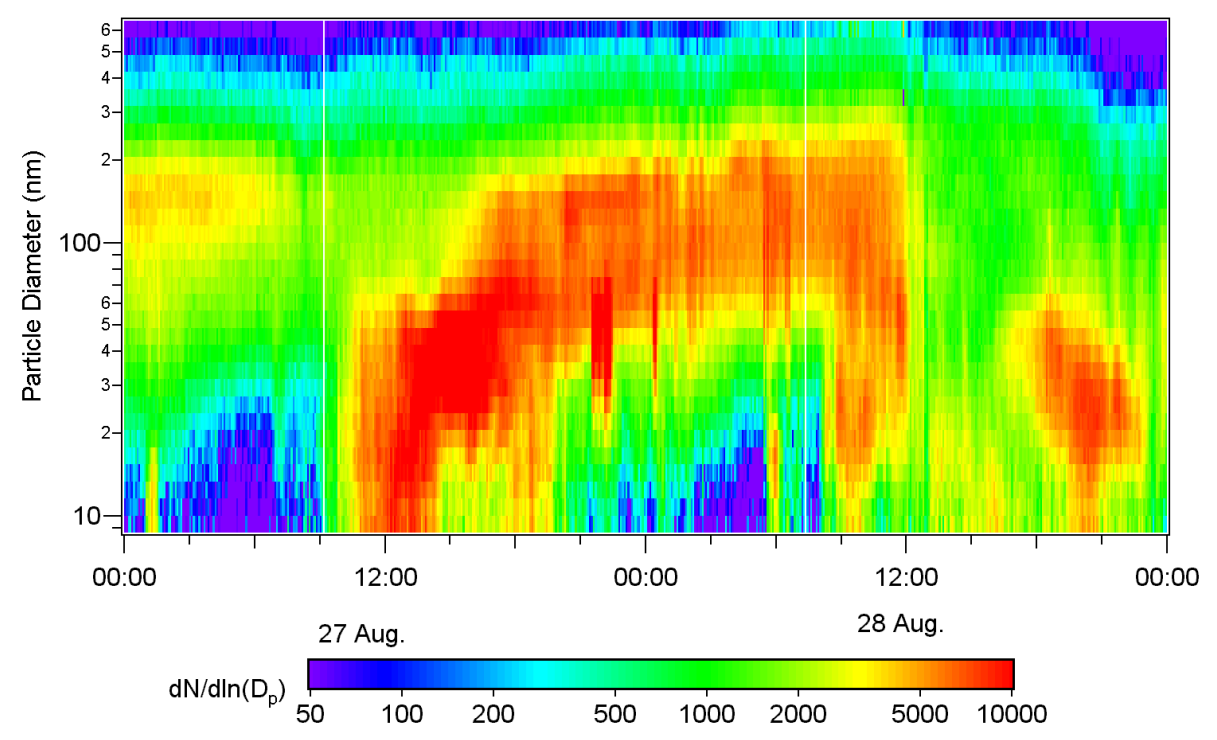

Fig. 8. DMA number size distributions for 27 and 28 August 2001 at Eagle Ridge showing overnight growth.

this mode decreased from 4100 to 3600 particles $\mathrm{cm}^{-3}$ during the growth period. The Aitken mode particles were bimodal, we call the two groups the "emission mode" and the "growth mode". The emission mode had $D_{N M D}=18.0 \mathrm{~nm}$ and $\sigma=0.70 ; N$ varied between 11000 and 17000 particles $\mathrm{cm}^{-3}$ with a downward trend during the latter half of the growth period. The growth mode was extremely narrow with $D_{N M D}$ increasing from 29 to $38 \mathrm{~nm}, \sigma$ increasing from 0.22 to 0.30 , and $N$ increasing from 3000 to 10000 particles $\mathrm{cm}^{-3}$.

The continued presence of a substantial concentration of emission mode particles suggests a continued source of these particles that then grew by condensation and coagulation to produce the growth mode particles. Growth by condensation and by coagulation with much smaller particles produces very narrow size distributions; this likely accounts for the sharp decrease between 40 and $60 \mathrm{~nm}$. The continued supply and growth of much smaller particles creates the "tail" to smaller sizes and the increasing number in the growth mode. Using estimated coagulation rate constants with the measured size distributions indicates that coagulation was a significant, but not the dominant, process during this time. This suggests that the growth must have been mostly by condensation, with a condensation growth rate between 5 and $10 \mathrm{~nm} \mathrm{hr}^{-1}$. Similar, but less dramatic, events occurred on the afternoons of 16, 27, 30, and 31 August.

The TDMA data, shown in Fig. 6, shows that the organic fraction at both 50 and $114 \mathrm{~nm}$ decreased from 0.8 to 0.6 during the period of particle growth. This suggests that the gasto-particle conversion process was mainly either the oxidation of $\mathrm{SO}_{2}$ to sulfate or the formation of $\mathrm{NH}_{4} \mathrm{NO}_{3}$. However, the $\mathrm{SO}_{2}$ mixing ratios were generally one ppbv or less during this period, so the latter possibility seems more likely.
At about 15:20, the integrated number concentration and the number density at $40 \mathrm{~nm}$ began to drop sharply, the number density at about $100 \mathrm{~nm}$ began to increase, and the peak moved from $130 \mathrm{~nm}$ to $100 \mathrm{~nm}$; this is shown in Fig. 7. This behavior suggests the mixing of two different air masses. However, $\mathrm{CO}$ and $\mathrm{NO}_{\mathrm{x}}$ remained nearly constant while this occurred.

\subsubsection{Overnight growth event: Monday, 27 August through Tuesday, 28 August}

From 26 August through 30 August, it appeared that another smog episode was beginning to develop, but no strong blocking pattern formed and daytime mixing heights generally reached more than $1000 \mathrm{~m}$ (Snyder and Strawbridge, 2004). During this period the daytime winds at the site were generally from the northwest. This daytime wind direction was uncommon during the rest of the study.

Monday, 27 August had a strong similarity to 15 August, but was unique in that the aerosol brought to the site in the growing boundary layer continued to be observed throughout the following night and into the next morning; this is shown in Fig. 8. This may have been associated with the fact that there was little, if any, nocturnal inversion on the morning of the 28th (Snyder and Strawbridge, 2004). On the morning of the 27th the aerosol in the residual boundary layer had a maximum at about $140 \mathrm{~nm}$. Boundary layer growth brought a large number of ultrafine particles to the site between 08:30 and 10:30; this was accompanied by increases in $\mathrm{CO}$ and $\mathrm{NO}_{\mathrm{x}}$ and a decrease in $\mathrm{O}_{3}$. The freshly emitted particles were smaller than on the 15 th indicating that they had undergone less coagulation, possibly due to weaker confinement under the nocturnal inversion. From 12:30 to 14:30 there was a particle growth event that was very much 


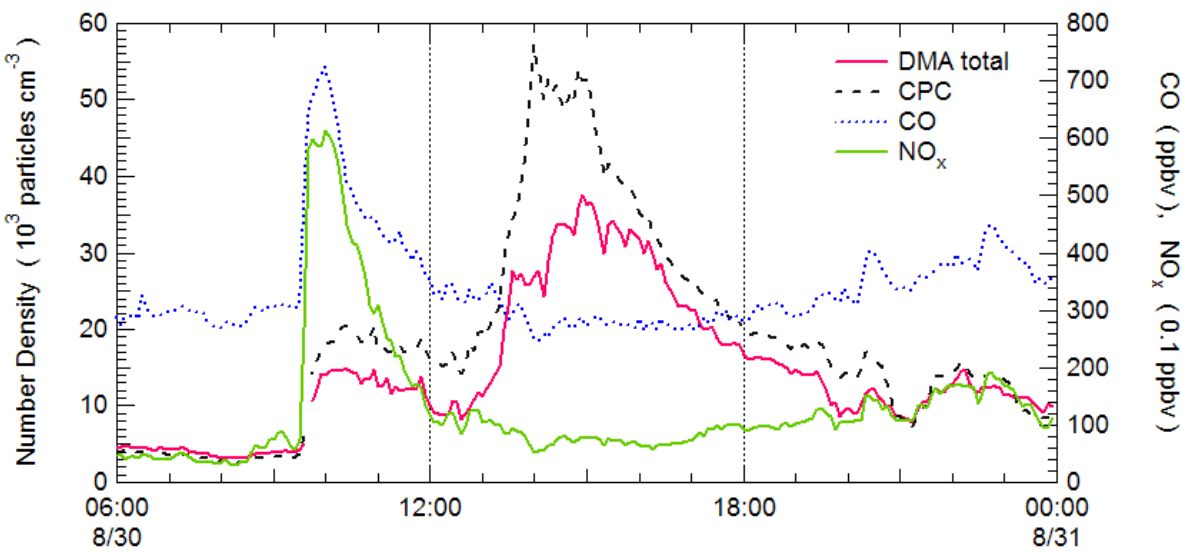

Fig. 9. Variation of particle concentrations and mixing ratios of $\mathrm{CO}$ and $\mathrm{NO}_{\mathrm{x}}$ on 30 August at Eagle Ridge.

like the one on the afternoon of the 15th. After 14:00, the particles below $20 \mathrm{~nm}$ nearly disappeared and from 14:30 on the size distribution appeared to evolve by both coagulation and condensation: the number concentration decreased while the volume increased. After about 20:00 there was a single broad accumulation mode except for times when there were brief intrusions of another air mass. This mode persisted until 11:50 on the morning of the 28th, after which aerosol concentrations, $\mathrm{CO}$ and $\mathrm{NO}_{\mathrm{x}}$ all dropped steeply, indicating a change in air mass. The median diameter of this mode increased from about $80 \mathrm{~nm}$ at 20:00 to about $120 \mathrm{~nm}$ at 04:00 the next morning. This can have been only partially due to coagulation since the number concentration in this mode decreased only from about 11500 to 9500 particles $\mathrm{cm}^{-3}$ during this time.

\subsubsection{Localized pollution events: Thursday, 30 August}

On Thursday, 30 August there were dramatic increases in $\mathrm{CO}, \mathrm{NO}_{\mathrm{x}}, \mathrm{O}_{\mathrm{x}}$, particle number, and particle volume at about 09:30, followed by large decreases over the next few hours, as shown in Fig. 9. Since visibility was not as poor and $\mathrm{O}_{3}$ concentrations were not as high as at the start of the study, these high pollutant concentrations appear to have been relatively localized. $\mathrm{CO}$ reached $700 \mathrm{ppbv}$ and $\mathrm{NO}_{\mathrm{x}}$ reached 60 ppbv; these were the highest concentrations observed during the study. The large increases in number concentration were for particles of about 20 to $25 \mathrm{~nm}$ diameter, as on the most polluted days. Thus, these small particles appear to be the result of direct emissions. The increases in particulate volume were due to increases in the number of accumulation mode particles with diameters of 400 to $500 \mathrm{~nm}$; this was very different from what normally occurred when polluted air was brought to the site by the growing mixed layer. As seen in Fig. 9, the mid-morning increase in pollution was followed by a rapid decrease, so that by 13:00 CO had returned to about $270 \mathrm{ppbv}$ and $\mathrm{NO}_{\mathrm{x}}$ had dropped to 5 to $10 \mathrm{ppbv}$. These decreases were too large to be explained solely by dilution into a growing boundary layer since they would imply an eventual boundary layer height in excess of $3 \mathrm{~km}$.

From 12:00 to 13:30, odd oxygen increased at about $7 \mathrm{ppbv} \mathrm{hr}^{-1}$, indicating that significant photochemistry was occurring. There was a large increase in particle number concentration beginning at 12:40. This was not associated with any change in trace gas concentrations, but it was not due to local nucleation since both the CPC and DMA concentrations increased at the same time. The size distributions show that this initial increase was primarily due to $30 \mathrm{~nm}$ diameter particles; this may clearly be seen in Fig. 10. At about 14:00, after which $\mathrm{NO}_{x}, \mathrm{CO}$ and $\mathrm{O}_{3}$ were nearly constant, the number maximum shifted from $30 \mathrm{~nm}$ to between 10 and $20 \mathrm{~nm}$. These particles may have been formed by local nucleation, perhaps beginning when the odd oxygen started to increase at 12:00. The size distribution then began to shift to larger sizes so that the maximum was at $40 \mathrm{~nm}$ by 16:00. During this growth event the size distributions had an asymmetric shape similar to those observed on 15 August.

\subsection{Nucleation days}

\subsubsection{Nucleation on clean days: Friday, 17 August through Monday, 20 August}

During this period, the overall air flow in the lower Fraser Valley was an outflow, with a weak inflow during the afternoons. The outflow brought clean air to the site from the mountains. Maximum mixing heights were over $1500 \mathrm{~m}$. At the site, nighttime winds were generally from the north or east (outflow) while daytime winds were from the west and southwest (inflow). During the mornings this was opposed to the overall outflow in the valley. Skies were generally overcast or partly cloudy. No nocturnal inversion formed on the night of 16-17 August.

There are a number of features in common on these days. During the early morning hours, number distributions were 


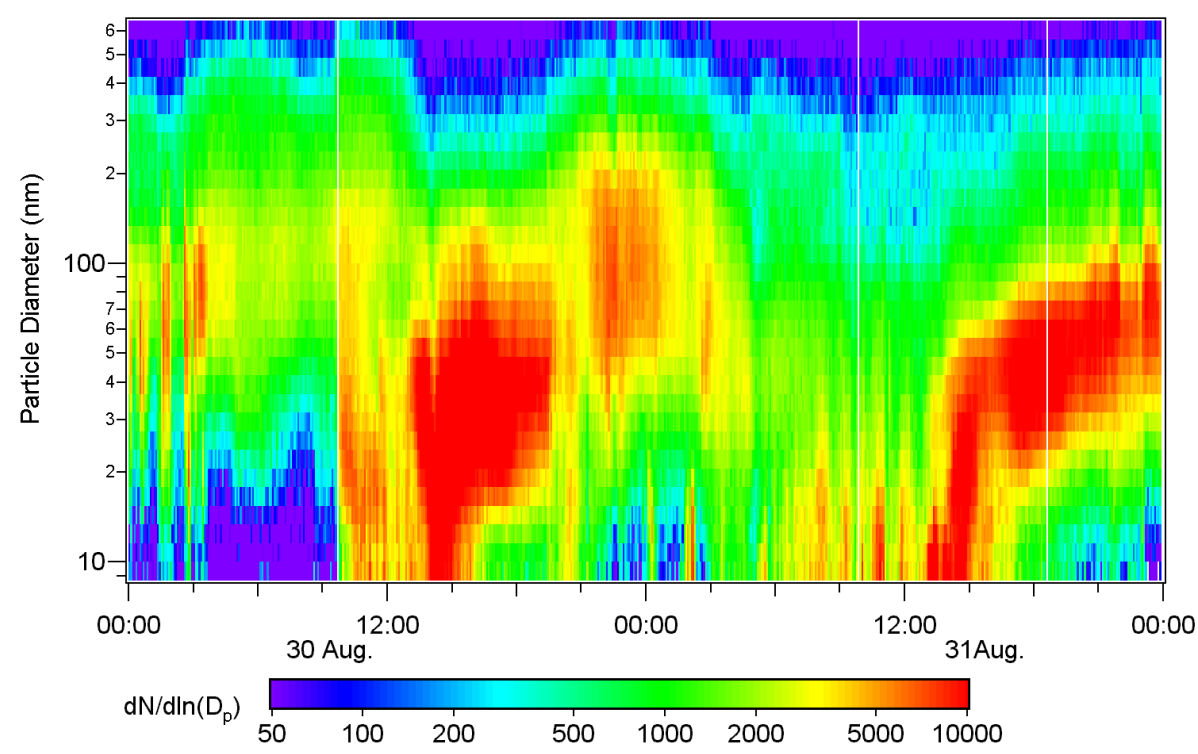

Fig. 10. DMA number size distributions for 30 and 31 August 2001 at Eagle Ridge showing the particle growth event on the 30th and the nucleation event on the 31 st.

Table 1. Summary of conditions for the onset of nucleation events. Particle concentrations measured by the CPC. All gas concentrations are ppbv. $\tau$ is the calculated $\mathrm{H}_{2} \mathrm{SO}_{4}$ lifetime with respect to condensation on the aerosol assuming a mass accomodation coefficient of unity.

\begin{tabular}{ccccccccccccc}
\hline Date & $\begin{array}{c}\text { Onset } \\
\text { Time }\end{array}$ & $\mathrm{RH}(\%)$ & $\mathrm{T}(\mathrm{C})$ & Wind & $\# \mathrm{~cm}^{-3}$ & $\tau(\mathrm{min})$ & $\mathrm{O}_{3}$ & $\mathrm{CO}$ & $\mathrm{NO}_{\mathrm{x}}$ & $\mathrm{UV}\left(\mathrm{W} \mathrm{m}^{-2}\right)$ & $\begin{array}{c}\text { Peak } \\
\mathrm{Time}^{2}\end{array}$ cm $^{-3}$ \\
\hline $8 / 17$ & $12: 05$ & 77 & 17 & W & 7500 & 12 & 10 & 220 & 9 & NA & $13: 55$ & 33,000 \\
$8 / 18$ & $10: 15$ & 72 & 15 & WSW & 7500 & 15 & 17 & 200 & 8 & 30 & $14: 35$ & 47,000 \\
$8 / 19$ & $10: 30$ & 74 & 15 & SW & 7800 & 13 & 18 & 170 & 9 & 29 & $11: 00$ & 35,000 \\
$8 / 20$ & $11: 20$ & 69 & 17 & WSW & 9500 & 9 & 17 & 190 & 11 & 36 & $13: 35$ & 50,000 \\
$8 / 23$ & $09: 45$ & 94 & 13 & SSE & 3600 & 27 & 19 & 210 & 5 & NA & $12: 45$ & 9100 \\
$8 / 31$ & $11: 40$ & 95 & 15 & SW & 8000 & 28 & 16 & 260 & 5 & 14 & $13: 00$ & 41,000 \\
\hline
\end{tabular}

dominated by an Aitken mode with a maximum at 50 to $80 \mathrm{~nm}$. There was also an accumulation mode with a much smaller number at about $300 \mathrm{~nm}$; on the 20th this was barely discernable. Although the detailed distributions were somewhat variable from one day to the next, they were quite constant with time on any given morning. Before 04:00, there were sometimes significant numbers of particles below $20 \mathrm{~nm}$ diameter. Between 08:00 and 10:00 there were some increases in sub- $20 \mathrm{~nm}$ particles that were associated with $\mathrm{NO}_{\mathrm{x}}$ and $\mathrm{CO}$; these may have been from vehicle emissions reaching the site in the growing boundary layer.

On each of these days there was a strong local nucleation and growth event, a summary of conditions for these events is given in Table 1. Figure 11 shows the size distribution data for 17 and 18 August. The nucleation events were characterized by the CPC number concentration rising sharply followed by a sharp increase in the integrated DMA number concentration after a delay of $90 \mathrm{~min}$ on the 17 th and 15 to $25 \mathrm{~min}$ on the other days. Figure 12 shows this behavior for the 17th. The delay before the increase in the DMA number indicates that the initial increase in CPC concentration was due to particles at sizes below the DMA lower limit of $9 \mathrm{~nm}$; these particles then grew until they were large enough to be detected by the DMA.

Once the DMA concentrations began to increase, the size distributions showed that the number maximum was below $10 \mathrm{~nm}$; this is also consistent with recent homogeneous nucleation. The size distributions showed significant growth of these newly formed particles; Fig. 13 shows this growth for August 18. For the most part, the maximum in the size distribution was near or below the DMA lower limit of $9 \mathrm{~nm}$, although it did reach about $17 \mathrm{~nm}$ at 13:30 on the 20th. This makes it difficult to make meaningful estimates of growth rates. Rough estimates, using both the size distribution and CPC data, indicate that diameter growth rates on these days were in the range of 5 to $10 \mathrm{~nm} \mathrm{hr}^{-1}$; these are somewhat larger than the previously reported growth rates cited in the Introduction. Total number concentrations, as measured by 


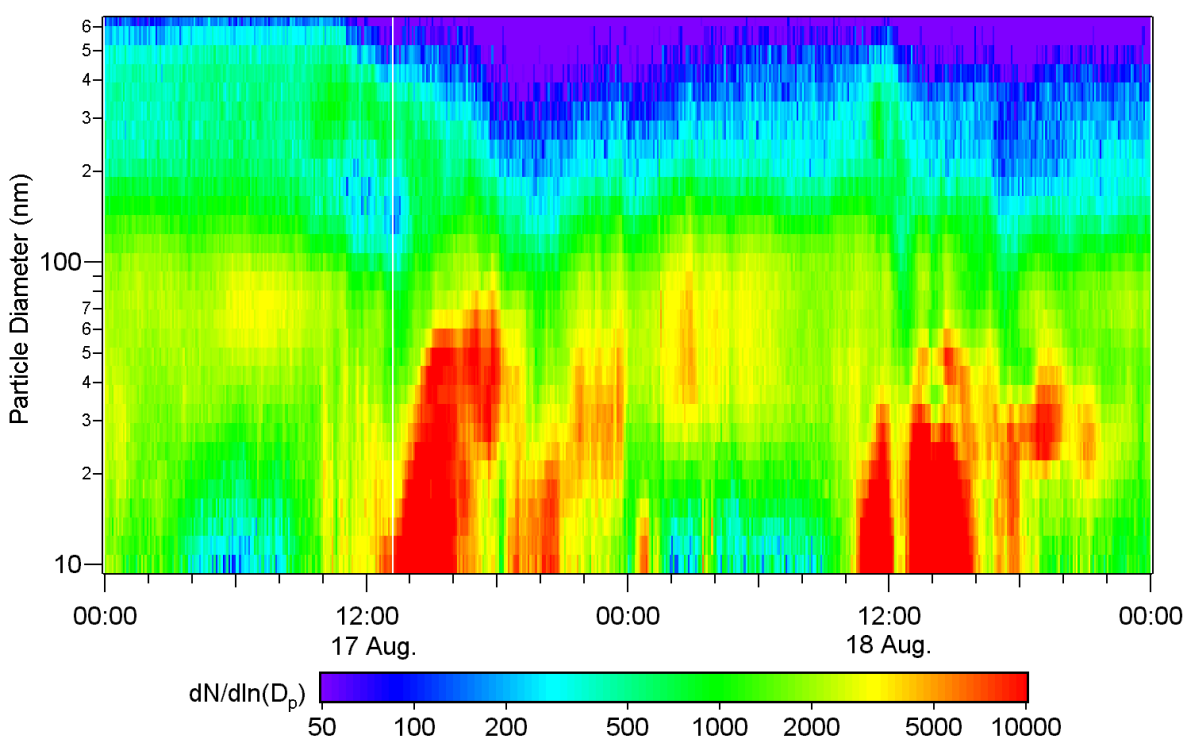

Fig. 11. DMA number size distributions for 17 and 18 August 2001 at Eagle Ridge showing nucleation and growth events on both days.

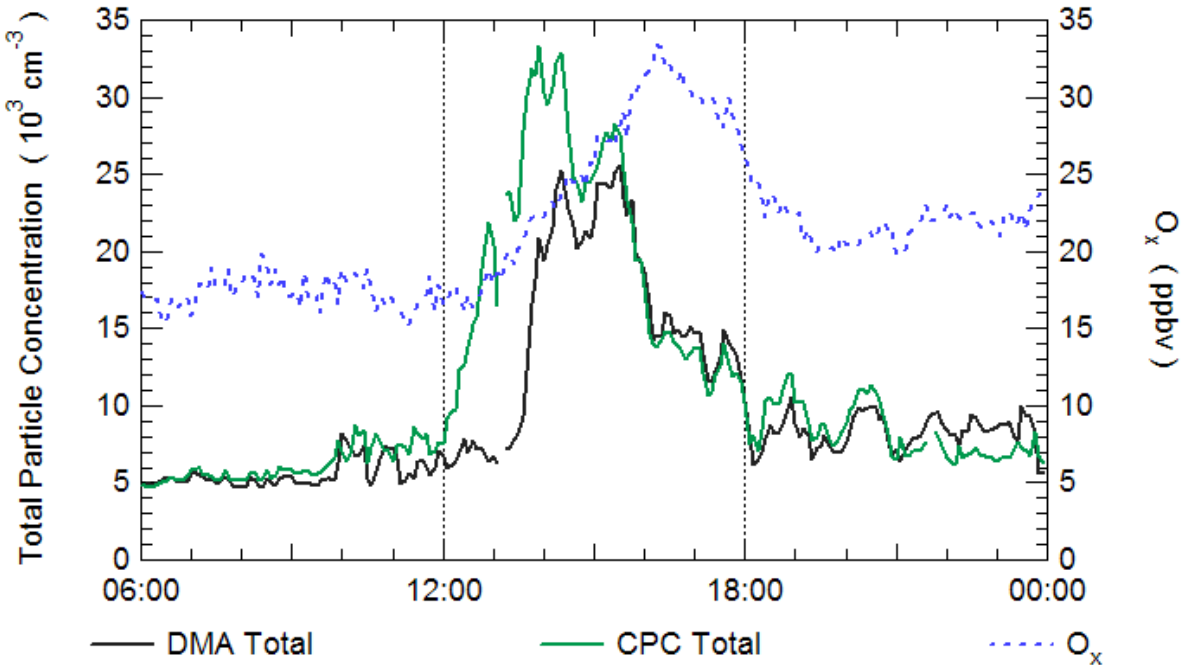

Fig. 12. Variation of particle number concentration and $\mathrm{O}_{3}$ on 17 August. The onset of photochemistry at about noon triggers increases in $\mathrm{O}_{3}$ and ultrafine particles; the delay in the increase in the DMA total is due to the time required for the newly nucleated particles to grow to the minimum detectable size of about $9 \mathrm{~nm}$.

the CPC, reached 3.5 to $5.0 \times 10^{4} \mathrm{~cm}^{-3}$ with the maximum DMA totals being about two-thirds as large. This is reasonable since many of the particles were below the DMA range, but the CPC numbers may be somewhat off since the CPC was in its photometric mode.

On each day, the onset of nucleation (at 12:00 on the 17 th, $10: 00$ on the 18 th, $10: 30$ on the 19 th, and 11:20 on the 20th) was associated with a thinning or clearing of cloud cover, suggesting that these events were driven by photochemistry. No UV measurements were available for the 17th, but on the other days, nucleation started soon after an in- crease in UV flux past $25 \mathrm{~W} \mathrm{~m}^{-2}$ (peak UV levels were a little over $40 \mathrm{~W} \mathrm{~m}^{-2}$ ). This association of nucleation with UV resembles the behavior reported by Birmili and Wiedensohler (2000). At about the same time, the mixing ratio of odd oxygen $\left(\mathrm{O}_{\mathrm{x}}=\mathrm{O}_{3}+\mathrm{NO}_{2}\right)$ began to increase (see Fig. 12), as expected if significant photochemistry was occurring. The rate of odd oxygen increase was about $5 \mathrm{ppbv} \mathrm{hr}^{-1}$ on the 17th and 18th and about $2 \mathrm{ppbv} \mathrm{hr}^{-1}$ on the 19th and 20th. On all of these days $\mathrm{SO}_{2}$ was near or below its detection limit; thus, it appears that the growth (and perhaps also the nucleation) was driven by the oxidation of organic 


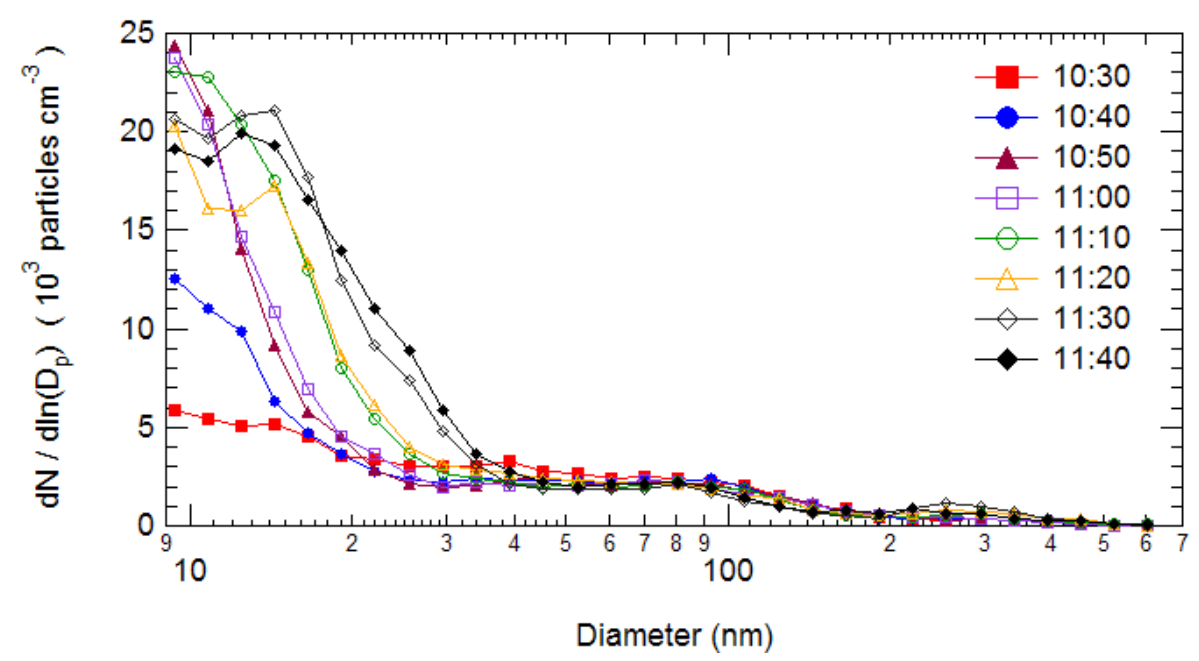

Fig. 13. Evolution of particle size distributions as a result of nucleation and growth on 18 August. Times are for the start of each five minute scan. For clarity, only every second scan is shown.

compounds. Since these were relatively clean days (for the most part, $120-200$ ppbv $\mathrm{CO}$ and $5-10$ ppbv $\mathrm{NO}_{\mathrm{x}}$ ), it is probable that the organic compounds were biogenic in origin.

During the onset of nucleation on 18 and 19 August, the hTMDA data indicate that the organic fraction of 50 and $114 \mathrm{~nm}$ particles was in the range of 0.6 to 0.8 and appeared to have been decreasing during the nucleation events. However, the apparent trend may have been simply due to variability in the data. Even if the organic fraction was constant, it suggests that, following the nucleation event, a significant portion of the condensing material was inorganic, in spite of the low concentrations of $\mathrm{SO}_{2}$ observed during these events. Another possibility is that the condensing material consisted largely of semi-volatile organic compounds that were more soluble in organic particles than in sulphate particles and so preferentially condensed on the newly formed organic particles. This type of selective growth of newly formed particles has been previously suggested by Mäkelä et al. (1997).

\subsubsection{Nucleation following rain: Friday, 31 August}

This day resembled the clean days in a number of respects. Winds were from the north and northwest and $\mathrm{NO}_{\mathrm{x}}$ and $\mathrm{O}_{\mathrm{x}}$ were comparable to the clean days but $\mathrm{CO}$ was somewhat higher (mostly 250-320 ppbv). During the morning there were large concentrations of ultrafine particles associated with $\mathrm{NO}_{\mathrm{x}}$. Between 11:00 and 11:40 it rained heavily, resulting in a $50 \%$ decrease in particle number concentrations. Immediately after this there was a nucleation event with the CPC number rising sharply at 11:40 and the DMA number rising sharply $85 \mathrm{~min}$ later. The size distributions, shown in Fig. 10, indicated that nucleation and growth was occurring. Peak numbers of particles were comparable to those observed on the other nucleation days. Prior to the onset of nucleation, the DMA total number concentration was about
$4000 \mathrm{~cm}^{-3}$, however the bulk of these particles had diameters below $20 \mathrm{~nm}$ so that calculated lifetimes for condensation of $\mathrm{H}_{2} \mathrm{SO}_{4}(\mathrm{~g})$ were 20 to $40 \mathrm{~min}$; this was substantially longer than during the other nucleation events. This nucleation event coincided with a rise in UV intensity to $22 \mathrm{~W} \mathrm{~m}^{-2}$, rather lower than on the other nucleation days, and with the start of $\mathrm{O}_{\mathrm{x}}$ production of roughly $4 \mathrm{ppbv} \mathrm{hr}^{-1}$. Nucleation at a lower level of UV may have been enabled by the longer lifetimes for the condensation of trace gases on to the particles.

One significant difference on this day was that there was not a dramatic shift to cleaner air in the afternoon, although it does appear that there was some dilution of the aerosol from 14:30 to $16: 30$ followed by a return to the air mass containing the recently nucleated, growing aerosol after 16:30. This makes it possible to better follow the growth of the newly formed particles. The delay before the onset of the increase in the DMA number concentration implies a growth rate of less than $5 \mathrm{~nm} \mathrm{hr}^{-1}$ prior to 13:00. From 14:10 to 15:15 lognormal distributions can be fit to the data to obtain the number median diameter of the nucleation mode particles (prior to this, the number maximum was at or below the lower size limit of the DMA). These yield a growth rate of roughly $9 \mathrm{~nm} \mathrm{hr}^{-1}$ during this interval. From 17:35 to 21:20, the size distributions were monomodal with a number median diameter increasing from 38 to $57 \mathrm{~nm}$. During this time the change in number concentration was consistent with coagulation. Although this accounts for part of the increase in size, an additional condensational growth rate of about $3 \mathrm{~nm} \mathrm{hr}^{-1}$ is also required. On this day, hTDMA data was only available after 14:00. After 17:00 the particle organic fraction very gradually increased from 0.7 to 0.9 . This indicates that the condensational growth observed in the late afternoon and early evening was due to organic compounds. 


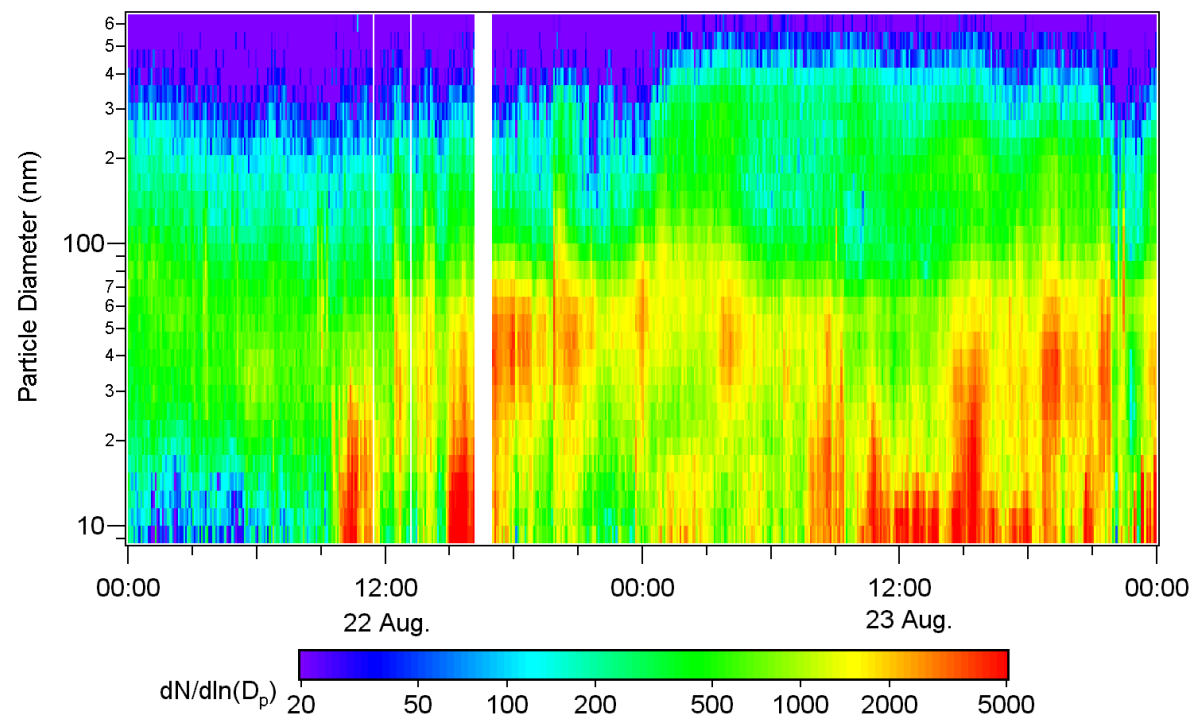

Fig. 14. DMA number size distributions for 22 and 23 August 2001 at Eagle Ridge. There was no data from 16:00 to 17:00 on 22 August due to a power outage. On these days it rained frequently. There were occasional pulses of nucleation mode particles, some of which were associated with $\mathrm{NO}_{\mathrm{x}}$ and some not.

\subsection{Rain days}

Rain began on 21 August and continued through the early morning of 24 August. During this period, particle concentrations were low, generally near 5000 particles $\mathrm{cm}^{-3}$. Size distributions for 22 and 23 August are shown in Fig. 14. From 23:00 on 21 August to 09:30 on 22 August, total number concentrations were below 2000 particles $\mathrm{cm}^{-3}$; these were the lowest concentrations observed during this study. During this time, the hTDMA data indicate that the particle organic fraction steadily increased until reaching unity. For the most part, size distributions were monomodal with the maximum varying between 40 and $70 \mathrm{~nm}$. The size distributions were occasionally dominated by large numbers of ultrafine particles, especially during the daytime on $23 \mathrm{Au}$ gust. The hTMDA data show that for this day particles were externally mixed due to the introduction of more hygroscopic particles (with higher inorganic fraction). While the organic fraction for the less hygroscopic mode was close to unity, the organic fraction for the hygroscopic mode started at 0.3 and increased to 0.7 as the day progressed. On the $23 \mathrm{rd}$ the wind was generally from the southwest, and therefore likely to contain higher levels of pollutants, while on the previous two days it was mostly from the east or north. Also, during the daytime on 23 August the rain was only an intermittent light drizzle. Occasionally, the maximum of the number distribution was at or below the lower size limit of the DMA. In general, the large numbers of ultrafine particles occurred when the wind was more southerly.

The ultrafine particles were most often associated with higher mixing ratios of $\mathrm{NO}_{\mathrm{x}}$ although this association was weaker for the very small particles $(9$ to $12 \mathrm{~nm}$ ) than for the ones with diameters around $20 \mathrm{~nm}$. $\mathrm{NO}_{\mathrm{x}}$ was mostly around $5 \mathrm{ppbv}$ during this period, but at times went as high as 17 ppbv. Higher concentrations of particles near the distribution maxima were also associated with higher levels of $\mathrm{NO}_{\mathrm{x}}$. The best correlation with $\mathrm{NO}_{\mathrm{x}}$ was obtained for the DMA total $\left(\mathrm{R}^{2}=0.49\right)$, rather than for any particular size, with a weaker correlation between $\mathrm{NO}_{\mathrm{x}}$ and the $\mathrm{CPC}$ total $\left(\mathrm{R}^{2}=0.37\right)$; this suggests that the smallest particles, at or below $10 \mathrm{~nm}$, were not associated with $\mathrm{NO}_{\mathrm{x}}$.

From 10:00 to 11:00 on 22 August and from 10:45 to 13:45 on 23 August, the size distributions were suggestive of nucleation. This was much more pronounced on $23 \mathrm{Au}-$ gust, especially after 12:30, as shown in Fig. 15. During the event on 22 August, $\mathrm{NO}_{\mathrm{x}}$ was elevated but on $23 \mathrm{Au}-$ gust $\mathrm{NO}_{\mathrm{x}}$ was not elevated at all. Thus, the ultrafine particles on 23 August do not seem to have been due to direct emissions. One possibility is that nucleation was occurring immediately above the cloud top; the combination of high actinic flux and high $\mathrm{RH}$ makes that region extremely suitable for nucleation (Clarke et al., 1999). Thus, entrainment of air from just above the cloud may have been responsible for the nucleation mode particles observed at these times. On the 22nd, ceiling heights, measured at the Abbotsford airport (about $10 \mathrm{~km}$ west of the site), were about $500 \mathrm{~m}$ and on the 23rd, ceiling heights increased from 900 to $1500 \mathrm{~m}$ at about noon.

A remarkable feature of the aerosol during this rainy period was the sometimes almost complete absence of inorganic material in the aerosol, this is discussed in more detail by Aklilu and Mozurkewich (2004). 


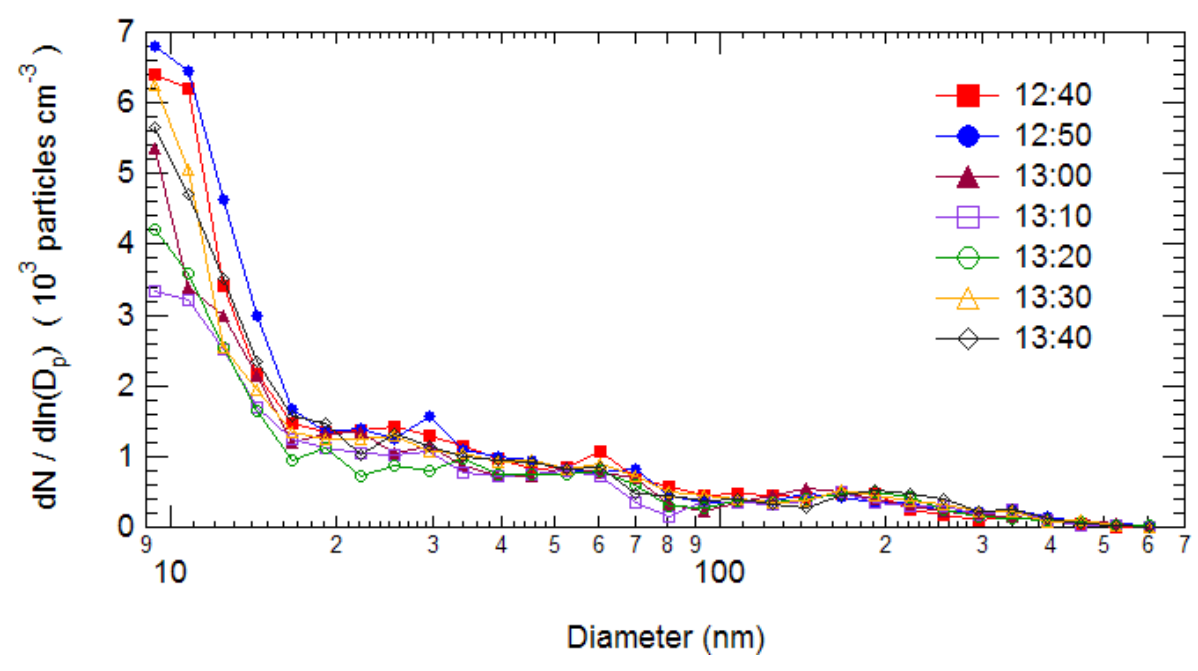

Fig. 15. Particle size distributions showing what appear to be recently nucleated particles on 23 August, an overcast day with light rain. Times are for the start of each five minute scan. For clarity, only every second scan is shown.

\section{Conclusions}

A general feature of the particle size distributions was that during the early morning hours (before and shortly after sunrise), the number size distributions tended to be fairly constant, as might be expected for a site located above the nocturnal inversion. These early morning distributions usually had a single maximum; on cleaner days, the maximum was at 40 to $80 \mathrm{~nm}$ diameter while on more polluted days it was at 100 to $140 \mathrm{~nm}$. There was sometimes also a shoulder in the distribution at about $200 \mathrm{~nm}$. On most days, ultrafine particles, with diameters of 10 to $20 \mathrm{~nm}$, were also sporadically observed during the early morning hours; on occasion they dominated the size distributions. These particles were usually associated with increased $\mathrm{NO}_{\mathrm{x}}$. Because of this and the fact that motor vehicles are known to produce ultrafine particles (e.g. Zhu et al., 2002), these ultrafine particles were most likely due to vehicle emissions being transported to the site from lower elevations.

From mid-morning through mid-afternoon, substantial concentrations of ultrafine particles were observed at the site. These were sometimes associated with transport and were sometimes the result of local nucleation. On most days these particles, along with elevated levels of $\mathrm{CO}$ and $\mathrm{NO}_{\mathrm{x}}$, were brought to the site in mid-morning in the growing mixed layer; this was especially pronounced during the smog event at the start of the study. Although an association between $\mathrm{CO}, \mathrm{NO}_{\mathrm{x}}$, and ultrafine particles was a normal feature at this site, their relative amounts were highly variable from day to day.

Nucleation events were observed on the cleaner days: 17 through 20 August and 31 August. These events began between 10:00 and 13:00 and were characterized by the CPC number concentration rising sharply with a similar increase in the integrated DMA number after a delay of 20 to $90 \mathrm{~min}$.
This suggest that the initial increase in CPC concentration was due to particles at sizes below the DMA lower limit of $9 \mathrm{~nm}$; these particles then grew until they were large enough to be detected by the DMA. Immediately following the increase in DMA integrated number concentration, the size distributions showed that the number maximum was below $10 \mathrm{~nm}$ and that the particles were growing. The diameter growth rates were approximately 5 to $10 \mathrm{~nm} \mathrm{hr}^{-1}$. The nucleation events seem to have been triggered when the UV flux reached about $25 \mathrm{~W} \mathrm{~m}^{-2}$. We can not identify the nucleating species, but the growth appears to have been driven by the photochemical oxidation of biogenic organic compounds.

On the afternoons of the more polluted days $(14,15,16$, 27, 29, 30 August), the particle size distributions showed what appears to be pronounced growth (5 to $10 \mathrm{~nm} \mathrm{hr}^{-1}$ ) with the rate of growth decreasing with increasing particle size. During these events the number distribution maximum increased in both number and size while the distributions developed a very steep decrease at sizes above the maximum (around $40 \mathrm{~nm}$ ) and a very gradual decease at smaller sizes. Thus, it appears that the particles were "piling up" in this size range. The mechanism for this growth appears to have been a combination of coagulation and condensation with emissions providing a continuous supply of nucleation mode particles. On 27 August, this growth continued through the evening and into the morning of 28 August.

On the rainy days (21 through 23 August) particle concentrations were low and size distributions were usually monomodal with the location of the maximum varying between 40 and $70 \mathrm{~nm}$. The size distributions were occasionally dominated by large numbers of ultrafine particles with diameters below $20 \mathrm{~nm}$. On these days the integrated DMA number concentrations generally correlated with $\mathrm{NO}_{\mathrm{x}}$ even though the variation in number was sometimes due to ultrafine particles and sometimes due to those in the main mode. 
However, it appeared that nucleation was occurring near the site around mid-day on 23 August.

On many afternoons there appears to have been a change in air mass at the site. Sometimes these changes resulted in variations in $\mathrm{NO}_{\mathrm{x}}, \mathrm{CO}$, and $\mathrm{O}_{3}$ as well as particulates, but on other days there were large changes in the aerosol number concentrations and size distributions with no corresponding changes in trace gas concentrations. These events are no doubt due to the complex meteorology at the site and make it difficult to quantitatively interpret the aerosol processes that occur (Snyder and Strawbridge, 2004).

On several nights there were steady decreases in particle number concentration accompanied by increases in particle size. This suggests that the aerosol was evolving by means of coagulation. Efforts to obtain average coagulation rate constants from this data yield values that are much higher than expected. This may be a result of dilution or advection.

Acknowledgements. We thank the Greater Vancouver Regional District for providing the $\mathrm{NO}_{\mathrm{x}}$ and $\mathrm{CO}$ data and R. Leaitch and $\mathrm{K}$. Hayden for providing the UV radiation data. Funding was provided by the Canadian Foundation for Climate and Atmospheric Science.

Edited by: T. Hoffmann

\section{References}

Aklilu, Y.-A. and Mozurkewich, M.: Determination of external and internal mixing of organic and inorganic aerosol components from hygroscopic properties of sub micrometer particles during a field study in the Lower Fraser Valley, Aerosol Sci. Technol., 38, 140-154, 2004.

Birmili, W. and Wiedensohler, A.: New particle formation in the continental boundary layer, Geophys. Res. Lett., 27, 3325-3328, 2000.

Birmili, W., Wiedensohler, A., Plass-Dülmer, C., and Berresheim, H.: Evolution of newly formed aerosol particles in the continental boundary layer: A case study including $\mathrm{OH}$ and $\mathrm{H} 2 \mathrm{SO} 4$ measurements, Geophys. Res. Lett., 27, 2205-2208, 2000.

Buzorius, G.: Cut-off sizes and time constants of the CPC TSI 3010 operating at 1-3 lpm flow rates, Aerosol Sci. Technol., 35, 577585,2001

Chan, T. W. and Mozurkewich, M.: Measurement of the coagulation rate constant for sulfuric acid particles as a function of particle size, J. Aerosol Sci., 32, 321-339, 2001.

Clarke, A. D.: Atmospheric nuclei in the remote free troposphere, J. Atmos. Chem., 14, 479-488, 1992.

Clarke, A. D., Kapustin, V. N., Eisele, F. L., Weber, R. J., and McMurry, P. H.: Particle production near marine clouds: sulfuric acid and predictions from classical binary nucleation, Geophys. Res. Lett., 26, 2425-2428, 1999.

Covert, D. S., Kapustin, V. N., Quinn, P. K., and Bates, T. S.: New particle formation in the marine boundary layer, J. Geophys. Res., 97, 20 581-20 587, 1992.

De Reus, M., Ström, J., Kulmala, M., Pirjola, L., Lelieveld, J., Schiller, C., and Zöger, M.: Airborne aerosol measurements in the tropopause region and the dependence of new particle forma- tion on preexisting particle number concentration, J. Geophys. Res., 103, 31 255-31 263, 1998.

Dick, W. D., Saxena, P., and McMurry, P. H.: Estimation of water uptake by organic compounds in submicron aerosols measured during the southeastern aerosol and visibility study, J. Geophys. Res., 105, 1471-1479, 2000.

Hegg, D. A., Radke, L. F., and Hobbs, P. V.: Particle production associated with marine clouds, J. Geophys. Res., 95, 1391713 926, 1990.

Kulmala, M., Dal Maso, M., Mäkelä, J. M., Pirjola, L., Väkevä, M., Aalto, P., Miikkulainen, P., Hämeri, K., and O’Dowd, C. O.: On the formation, growth and composition of nucleation mode particles, Tellus B, 53, 479-490, 2001a.

Kulmala, M., Hämeri, K., Aalto, P. P., Mäkelä, J. M., Pirjola, L., Nilsson, E. D., Buzorius, G., Rannik, U., Dal Maso, M., Seidl, W., Hoffman, T., Janson, R., Hansson, H. C., Viis, Y., Laaksonen, A., and O'Dowd, C. D.: Overview of the international project on biogenic aerosol formation in the boreal forest (BIOFOR), Tellus B, 53, 324-343, 2001b.

Leaitch, W. R., Bottenheim, J. W., Biesenthal, T. A., Li, S.-M., Liu, P. S. K., Asalien, K., Dryfhout-Clark, H., and Hopper, F.: A case study of gas-to-particle conversion in an eastern Canadian forest, J. Geophys. Res., 104, 8095-8111, 1999.

Li, S.-M.: A concerted effort to understand the ambient particulate matter in the Lower Fraser Valley, Atmos. Environ., in press, 2004.

Mäkelä, J. M., Aalto, P., Jokinen, V., Pohja, T., Nissinen, A., Palmroth, S., Markkanen, T., Seitsonen, K., Lihavainen, H., and Kulmala, M.: Observations of ultrafine aerosol particle formation and growth in boreal forest, Geophys. Res. Lett., 24, 1219-1222, 1997.

O’Dowd, C. D., Davison, B., Lowe, J. A., Smith, M. H., Harrison, R. M., and Hewitt, C. N.: Biogenic sulphur emissions and inferred sulphate CCN concentrations in and around Antarctica, J. Geophys. Res., 102, 12 839-12 854, 1997.

O’Dowd, C. D., Hämeri, K., Mäkelä, J. M., Pirjola, L., Kulmala, M., Jennings, S. G., Berresheim, H., Hansson, H. C., de Leeuw, G., Kunz, G. J., Allen, A. G., Hewitt, C. N., Jackson, A., Viisanen, Y., and Hoffmann, T.: A dedicated study of new particle formation and fate in the coastal environment (PARFORCE): Overview of objectives and achievements, J. Geophys. Res., 107, doi:10.1029/2001JD000555, 2002.

Oberdörster, G.: Pulmonary effects of inhaled ultrafine particles, Internat. Archives Occupational Environ. Health, 74, 1-8, 2000.

Peng, C., Chan, M. N., and Chan, C. K.: The hygroscopic properties of dicarboxylic and multifunctional acids: measurements and UNIFAC predictions, Environ. Sci. Technol., 35, 4495-4501, 2001.

Pryor, S. C. and Barthelmie, R. J.: REVEAL II: Seasonality and spatial variability of particle and visibility conditions in the Fraser Valley, Sci. Total Environ., 257, 95-110, 2000.

Sceats, M. G.: Brownian coagulation in aerosols - the role of long range forces, J. Colloid Inter. Sci., 129, 105-112, 1989.

Schwartz, S. E.: The Whitehouse Effect - shortwave radiative forcing of climate by anthropogenic aerosols: an overview, J. Aerosol Sci., 27, 359-382, 1996.

Snyder, B. J. and Strawbridge, K. B.: Meteorological summary of the Pacific 2001 air quality field study, Atmos. Environ., in press, 2004. 
Stanier, C., Khlystov, A., and Pandis, S.: Nucleation events during the Pittsburgh air quality study: Description and relation to key meterological, gas phase, and aerosol parameters, Aero. Sci. Technol., 38(S1), 253-264, 2004.

Twomey, S.: Aerosols, clouds, and radiation, Atmos. Environ., 25A, 2435-2442, 1991.

Verheggen, B. and Mozurkewich, M.: Determination of nucleation and growth rates from observation of a $\mathrm{SO}_{2}$ induced atmospheric nucleation event, J. Geophys. Res., 107, doi:10.1029/2001JD000683, 2002.

Virkkula, A., Van Dingenen, R., Raes, F., and Hiorth, J.: Hygroscopic properties of aerosol formed by oxidation of limonen, $\alpha$ pinene, and $\beta$-pinene, J. Geophys. Res., 104, 3569-3579, 1999.

Weber, R. J., McMurry, P. H., Eisele, F. L., and Tanner, D. J.: Measurement of expected nucleation precursor species and 3-500-nm diameter particles at Mauna Loa observatory, Hawaii, J. Atmos. Sci., 58, 2242-2257, 1995.

Weber, R. J., Marti, J. J., McMurry, P. H., Eisele, F. L., Tanner, D. J., and Jefferson, A.: Measurements of new particle formation and ultrafine particle growth rates at a clean continental site, J. Geophys. Res., 102, 4375-4385, 1997.
Weber, R. J., McMurry, P. H., Mauldin, D. J., Tanner, D. J., Eisele, F. L., Brechtel, F. J., Kreidenweis, S. M., Kok, G. L., Schillawski, R. D., and Baumgardner, D.: A study of new particle formation and growth involving biogenic and trace gas species measured during ACE 1, J. Geophys. Res., 103, 16 385-16396, 1998.

Weingartner, E., Nyeki, S., and Baltensperger, U.: Seasonal and diurnal variation of aerosol size distributions $(10<D<750 \mathrm{~nm})$ at a high Alpine site (Jungfraujoch $3580 \mathrm{~m}$ asl), J. Geophys. Res. 104, 26 809-26 820, 1999.

Wiedensoholer, A., Covert, D. S., Swietlicki, E., Aalto, P., Heintzenberg, J., and Leck, C.: Occurrence of an ultrafine particle mode less than $20 \mathrm{~nm}$ in diameter in the marine boundary layer during Arctic Summer and Autumn, Tellus B, 48, 213-222, 1996.

Woo, K. S., Chen, D. R., Pui, D. Y. H., and McMurry, P. H.: Measurement of Atlanta Aerosol Size Distributions: Observations of Ultrafine Particle Events, Aerosol Sci. Technol., 34, 75-87, 2001.

Zhu, Y. F., Hinds, W. C., Kim, S., Shen, S., and Sioutas, C.: Study of ultrafine particles near a major highway with heavy-duty diesel traffic, Atmos. Environ., 36, 4323-4335, 2002. 